\title{
Knowledge, complexity, power: social semiotics as metadiscipline
}

Bob Hodge*

Institute for Culture and Society, Western Sydney University, New South Wales, Australia.

Received: July 2020; Accepted: October 2020

\begin{abstract}
This article contributes to this special journal issue by developing concepts and methods from social semiotics to analyse, interpret and comment on text and ideas from the issue plus an RFS-project on interdisciplinarity, knowledge transfer and methodology convergence within and across STEM and HASS disciplines. It follows and extends this project's focus on three disciplines, politics, biology and linguistics, and connects them with emerging features of contemporary knowledge production, especially complex, problematic relations between scientific and non-scientific knowledges, and new forms of operations of power on knowledge.

The article develops a modified Kuhnian framework to argue that this project can be understood as a significant intervention into a currently unfolding crisis and opportunity in knowledge. It diagnoses crises of knowledge that stem from inadequacies in traditional disciplinary organisations when confronted by challenges and "wicked problems" arising from the scale and complexity of a hyper-connected world. It sees new opportunities arising from new forms of disciplinary organization, constituted by metadisciplinary structures and functions, within a Kuhnian framework of paradigms and metaparadigms. It uses social semiotics as tool and case study, to show how disciplines can evolve into metadisciplines, and demonstrate the productivity of metadisciplines within metaparadigm processes.
\end{abstract}

Keywords: social semiotics; complexity; knowledge transfer; interdisciplinarity; metadiscipline; paradigms; evolution

\section{INTRODUCTION}

This article uses social semiotics as a resource to reflect on ideas around the theme of this special journal issue especially as carried by its title, "Evolution of human capacities to know and act", and from the major Russian Scientific Foundation (RSF) project which supported the conference: "Knowledge transfer and convergence of methodological practices: interdisciplinary integration of politics, biology and linguistics"1 ${ }^{11}$ hereinafter "the Project".

The central object of this research is not just knowledge. This knowledge comes as part of an unstable dyad, knowledge-and-practice, formed by intrinsic relations between the two elements. Each affects the other in a complex system of a kind I argue appears in all domains of knowledge and life. These disciplines refer to three dimensions, held together in a complex structure. The knowledge is both about biology and is itself a biological process. It is about politics as well as being enmeshed in politics. It is about linguistics and communication, as well as being immersed in semiotics, language in all its modes.

In this scheme, interdisciplinarity is both object and method of an inquiry into disciplinarity itself. Recurring

\footnotetext{
* E-mail: b.hodge@westernsydney.edu.au

1 (RSF project 17-18-01536). I am grateful to all members of the team, especially to Ivan Fomin and Suren Zolyan, for sharing so many ideas and materials, and above all to Mikhail llyin, who not only shared his work but also provided a commentary on earlier forms of this article, referenced as "personal communication (PC)".
} 
complexities exacerbate the problems of defining this object. How can the problems of disciplinarity at this limit be understood purely in terms of disciplinary systems? In this situation I propose the concept of "metadiscipline" to indicate a place outside yet connected to specific disciplinary systems.

In what follows I use social semiotics as a convenient site from which to develop a meta-function capacity to help understand current crises of knowledge production and find ways to go beyond. My discussion already shows how crucial meanings are in understanding fundamental issues, needing interpretive disciplines like social semiotics as part of everyone's meta-disciplinary tool kit.

Metadisciplines need to be especially open and dynamic, richly connected to component disciplines and complementary metadisciplines. From the sciences I propose complexity science as another candidate meta-discipline. Philip Anderson, a founding father of complexity science, wrote as follows:

"The behaviour of large and complex aggregates of elementary particles, it turns out, is not to be understood in terms of a simple extrapolation of the properties of a few particles. Instead, at each level of complexity entirely new properties appear...

In this case we can see how the whole becomes not only more than but very different from the sum of its parts." (1972)

This is an ostensive definition, with fuzzy boundaries and unresolved contradictions. Anderson, a Nobel-prize winning physicist, takes his basic premise from Aristotle, an ancient philosopher. He takes an example from quantum physics, but the concept applies to biology and sociology, and is open to applications to meaning and thought, semiotics and psychology.

These qualities make it especially suitable to be a complementary metadiscipline. As metadiscipline it has high energy and low boundaries and can relate to or converge with other candidate metadisciplines, such as general biology or social semiotics. Metadisciplines can interact and combine more richly and unpredictably, especially when set, as modern forms of knowledge inescapably are, in a turbulent, chaotic world.

\section{KNOWLEDGE, STRUCTURE, CHANGE}

It is widely agreed that around 500 years ago a new, more powerful way of knowing the material world emerged abruptly, now known as "science" and "the sciences". This event and the set of knowledges it has produced are an essential part of the Project's inquiry into knowledge and method. It builds some categories into the Project's foundations, such as differences and similarities between "scientific" and "non-scientific" knowledges. It also raises some key empirical questions. Where did this new form of knowledge come from, and how compatible is it with older ways of knowing?

For instance, has the present dispensation evolved, in a relatively strict sense of the word, from the organization of knowledge 2000 years ago, in the nearly simultaneous civilisations of Greece and Rome, Egypt and the Middle East, India, China and Meso-America? Or further back, in the hypothesized emergence of homo sapiens sapiens in 150,000 BP? Or further back again, to a supposed common ancestor of cephalopods and primates who may have invented consciousness and semiosis (Godfrey-Smith 2020)?

The emergence of science is so important that it warrants slowing evolution's clock down and operating by different time scales, and the present is so important to us today we are justified in speeding the clock up. We need to understand patterns and rhythms of the present in their own terms, while also re-inserting them in longer histories. This scope in space and time requires nonlinear multiscalar theory (Hodge 2017). Within a flexible, dynamic chronology, science and its relations to non-scientific traditions of knowledge remain essential to understand knowledge today. Any comprehensive account of the "evolution of human capacities to act and know" needs to include and not be limited to the "scientific revolution" which appeared remarkably suddenly between 1450 and 1700 .

\section{KUHN AND INCOMMENSURABILITY}

To lay down some preliminary terms and concepts about science as a changing, developing system of knowledge I draw on TS Kuhn's work on science and its revolutions (1962), still the most-cited work on the philosophy of science over the past half century. Kuhn's theory of science and scientific revolutions has become part of a modern consensus, shared by many who no longer recognise where these ideas come from. In developing this set of ideas Kuhn turned his discipline of origin, physics, into an exemplary metadiscipline, history and philosophy of science.

At the heart of Kuhn's theory is the concept of paradigm, in a radical theory of a level of the organization of scientific knowledge deeper than "disciplines". Paradigms can be less than disciplines, radically different stages within the development of a discipline, or more, over-arching configurations of many disciplines. Before Kuhn, disciplines were accepted as blocks of knowledge, each separated from others by rules seen as coming from the nature of reality itself. Science was supposed to progress in linear steps, each stage closer to the truth.

Kuhn's theory was in important respects based on sociosemiotic principles within a metadisciplinary framework. He drew on a range of sources, including Gestalt psychology, Einstein's theories of relativity, and linguistics-especially Whorf (1956), who combined these traditions in his own metadisciplinary linguistics. From these and other sources, Kuhn developed the idea of incommensurability, that each paradigm-like different languages-constructs a closed universe of meanings, incompatible versions of reality, maintained and policed by a community. 
As Professor llyin pointed out to me, (PC 2020) "incommensurable" has a long history, starting with late Latin, but at its heart is a sense of mathematically generated disjunction around the act of measuring. Measuring itself is a primary act of the knowing mind. But "incommensurability" comes from within systems of measuring to make measurement itself difficult or impossible. It is a systemic contradiction, disabling systems from within.

Incommensurability plays a crucial role in the development of what has been called the post-Newtonian paradigm. Henri Poincaré laid early foundations of chaos theory by demonstrating incommensurability in the heart of the foundational achievement of the Newtonian paradigm, Newton's mathematics of the solar system. Newton himself was aware of a potential anomaly, that he could not show how future states of the three-body system of the sun, moon and earth could be predicted over many iterations. Poincaré won a prestigious prize for proving mathematically that this was not simply difficult but impossible. That is, different stages of this familiar system were incommensurable with each other.

The problem affected the paradigm more than reality itself. The moon was not going to crash into Earth as a result of Poincaré's maths. Similarly, Einstein's theory of relativity did not prove Newton wrong. It just brought out the effect of different frames that Newton had not incorporated, in which different calculations on different bases became possible.

\section{ANOMALIES}

According to Kuhn, most science is "normal" science, productively solving problems it sets itself, based on a core of agreed facts, theories and practices, judging success or failure by agreed standards. Crisis and revolution are aberrations, which happen not because any fact proves the paradigm wrong but because a significant anomaly defeats all attempts to explain it in current disciplinary terms (Hoyungen-Huene 1993).

These repeated failures finally precipitate crises in the paradigm community, though not with linear causality. For Kuhn as proto-social semiotician, scientific crises always have social dimensions. Breaks are unpredictable outcomes of multiple forces, producing non-linear (messy, uneven, chaotic) processes of change. These always involve politics. Old guards typically continue rear-guard actions, defending their discipline as long as they have power to do so. If they resist successfully, for Kuhn this does not prove they have the best theory. They may simply be better political players or have more powerful allies.

The world of policy studies provides a complementary idea, the concept of "wicked problems" (Conklin 2006). In the practical experience of these grounded thinkers, problems go from "challenging" to "hard" to "wicked" when they have a number of features, many of them socio-semiotic. "Wicked" problems have serious problems of definition; there is no agreement on exactly what the problem is, what its limits are, and what a solution would look like. Typically, consensus is impossible to achieve across different interests and experts. Notably, some apparently obvious solutions from one perspective or discipline make problems worse.

Kuhnian "anomalies" can be seen as one type of wicked problem, which resists solution because its complexity destabilizes the total system, which is otherwise partitioned off into component disciplines. From this perspective it is likely that anomalies will not be permanently solved. Rather they will continue to provoke and generate new theories.

I illustrate how these issues bear on world problems through the issue of the Covid-19 pandemic. Its status as anomaly, as "wicked problem", is shown by the fact that it is minimally a health, economic and political problem. Solutions of the health problems following normal guidelines exacerbate economic and political problems, and vice versa. Basic decisions about whose knowledge should prevail are contested across different scales, exposing questions of power and control. No discipline can oversee all others, and no world body combines the knowledge and power to make a difference.

The unfolding challenge of Covid-19 provokes a deeper understanding of the journal issue theme, "evolution of human capabilities to act and know". It provides evidence that this process has recently accelerated, demanding new developments in the organization of knowledge to match changes in the world to be explained and in social forms that organise those who support, influence or control those who supposedly know. The challenging, turbulent times we live in today are an ideal site for the knowledge experiment that the Project is conducting

\section{EVOLUTION AND REVOLUTION}

As stated above, Kuhn claims that terms from one paradigm cannot be exactly calibrated against those of another. I treat this as an original but problematic social semiotic proposition. I analyse it as such in a social semiotic framework, alongside a corollary I derive from Kuhn's proposition: terms from settled, disciplinary stages of knowledge may be similarly incommensurable from forms they take in metaparadigm conditions. That is, there may be commensurability barriers between paradigm levels as well as between individual paradigms, in what can be termed "vertical interdisciplinarity".

I use "evolution", a key term for the Project, as a test case. There is tension in Kuhn's theory between the normality of "normal" science, which produces knowledge continuously like a smooth machine, by "evolution", and the "revolutions" of his title. In some respects, his account of scientific progress seems like classic evolutionary theory, with paradigms competing in a process of natural selection. But revolutions in his theory as in the popular mind seem like the real engines of the growth of knowledge, associated with famous breakthroughs like those of Copernicus, Newton, Darwin and Einstein. 
To explore these issues, I take the example of Stephen Gould, described as the second most influential 20th-century historian of science (Shermer 2002). Gould was a successful mainstream scientist, who spent his entire academic career at Harvard University, then as now one of the world's top universities. From the outset he showed how a meta-disciplinary function can combine with disciplinary recognition. For instance, he reflected explicitly on the role of preconceived ideas in science in one of his most influential scientific articles (Eldridge, Gould 1972).

Gould and Eldridge argued against the then dominant model of evolutionary theory, that evolution always proceeds gradually. Instead they argued that the fossil record more often shows long stages of equilibrium, where there is very little real change, interrupted by moments when change is very rapid. Their biological theory mirrors Kuhn's theory of scientific thought, with good reason. Gould and Eldridge knew and admired Kuhn's work. The connection shows how metadisciplines can motivate scientific innovation.

Their theory was triggered by a Kuhnian anomaly in evolutionary theory, in this case a literal gap. If the mainstream account was correct, the fossil records should have contained many examples of transitions. In fact, there are very few. As Kuhn's theory predicted, mainstream theorists defended it by saying that the geological record was so poor that these didn"t survive. Not so, Gould and Eldridge responded: the record shows so few transitional species because they were concentrated in the brief moments of revolutionary explosion.

Punctuated equilibrium theory inserted a revolutionary/step model into biological orthodoxy, but its disruptive force was contained by disciplinary authorities. Some eminent evolutionists even tried to claim Gould was not really an evolutionist. Professor Gould of Harvard University could not be removed in that way, and his views were known and cited by other biologists. However, there is a strong tendency for the dominant position within a discipline to be taken as the view of that discipline, as agreed truth as far as outsiders are concerned.

The power of leaders of a discipline to control the status of truth in their discipline is usually considerable and invisible, normally supported by leaders of other disciplines. It is perhaps the greatest single barrier to interdisciplinary work today. It needs a social semiotic approach with disciplinary expertise and good politics to recognize when this is going on and contest it.

I apply some principles from complexity theory and social semiotics to explain this situation. A theory or paradigm like evolution usually has many causes-scientific ones stemming from the complex nature of reality, plus social causes, including power structures, plus semiotic factors, including concepts and forms of language. Likewise, even a single term as sign, such as "evolution" in this case, has many meanings.

In the issue title, "evolution of human capacities to act and know", "evolution" has both an everyday meaning, referring to any gradual change, and a scientific meaning, which connects more closely with biology. From reading Gould's work, we realize that that scientific meaning itself can split, producing a third meaning in which it is not contrasted to revolution but co-exists with it, in an expanded sense that is fully but ambiguously scientific.

The three levels correspond loosely to pre-paradigm thinking, paradigm thinking, and metaparadigm thinking. In good, productive scientists like Gould there is fruitful knowledge transfer between these three levels, which enables him to engage with terms and findings from other disciplines and fields of knowledge and innovate within his own. He is aware of incommensurability but can negotiate it creatively in practice.

\section{CHALLENGING DISCIPLINARITY}

The Project did not invent the problem of disciplinarity in modern systems of knowledge. The theme is prominent in STEM as in HASS disciplines. The problem is what to do about it. What is wrong and dysfunctional about the traditional set of disciplines, what might take their place, and how and where can the transition be understood and managed? In this section I look at different proposals for post-disciplinary knowledge, including the Project's. I argue that research into the issues of knowledge and interdisciplinarity posed by the title of this special issue requires a concept of metadisciplinarity, framed by the Kuhnian concept of a metaparadigm (1977, see Hodge 1978). In this section I use social semiotic methods to explore existing proposals, including social semiotics as candidate metadiscipline.

\section{METADISCIPLINARITY}

The pre-fix meta- comes from Aristotle, used of "metaphysics" as a reflection on basic principles of "physics". Especially in semiotics meta has acquired a sense of referring to a higher order level, as in Jakobson's "metalanguage", used in this sense by Randviir (2020) in this issue, and Bateson's influential idea of "metacommunication", communication about communication (1972).

In a personal communication Professor Ilyin (PC 2020) raised objections to this usage. He notes that "such a meaning of 'meta' poorly fits Greek $\mu \varepsilon \tau a$ ", which he derives from the Indo-European root ${ }^{*} m e$, within, in the middle, like the cognate word $\mu \varepsilon \sigma o s$, middle. I use social semiotics to comment on this intervention as well as responding to its substance.

Professor llyin is a good scholar, and what he says is correct. In disciplinary terms, I note that Professor Ilyin here speaks not out of the Linguistics discipline, which no longer addresses etymologies like this, but a previous paradigm, comparative philology, for which this was a core practice. In this moment Professor llyin is a metadisciplinary linguist. For social semiotics in metadisciplinary mode it is important to insist that in complex situations more than one meaning or interpretation can be right. 
Both his and my propositions can co-exist, both true to some degree and not-true to a degree.

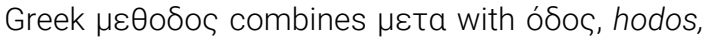
road. This word is a metaphor utilizing the literal meaning of $\mu \varepsilon \tau a$, "in the middle of a road, following steps along a road". However, meta also appears in an important, complex term, probably invented by Aristotle himself, metaphora. This word as in many classical Greek compounds with meta (meth before $h$ ) has connotations of change. There is a similar ambiguity in Latin trans, literally a spatial word, "across", but also implying change, as in transformare.

It is no coincidence that Aristotle, an exemplary metadisciplinary thinker, uses fuzzy terms like "metaphysics" and "metaphor," whose generative imprecision has produced an inexhaustible tradition of interpretation for more than 2000 years. Likewise, not coincidentally, I describe features of language and thought characteristic of metaparadigms drawing not on a linguist or philosopher but an engineer, Lotfi Zadeh, meta-disciplinary founder of Fuzzy Logic. His "Principle of Incompatibility" states:

"Stated informally, the essence of this principle is that as the complexity of a system increases, our ability to make precise and yet significant statements about its behaviour diminishes until a threshold is reached beyond which precision and significance (or relevance) become almost mutually exclusive characteristics." (Zadeh 1973, 28)

Metadisciplines of their nature deal with higher-level aspects of disciplinary systems, and need their main terms to be fuzzy, including their account of their own status as a kind of discipline. All potential component disciplines that feed into meta-disciplines are contested. Consequently, metadisciplines allow difference, contradiction, heterogeneity.

I revisit the key term, "method", in the Project from this perspective. "Method" in English has become associated with linear, step-by-step approaches, with the cognate "methodology" left to frame those practices with less linear ones. Metaparadigm thinkers need a more fuzzy term to refer to this range of practices. Perhaps the etymology of meta that Professor Ilyin recalls can be re-used for this purpose. Method could keep its current sense, and meta-hodos refer to metamethod, non-linear practices hovering above normal methods, reflecting on them, open to radical change. Or "metamethod" could serve the purpose with a less problematic linguistic innovation.

\section{INTERDISCIPLINARITY AND ITS OTHERS}

The Project refers to "interdisciplinary integration". "Interdisciplinarity" is the most common word used to describe interventions into disciplinary structures, yet is often criticised as too weak. Professor llyin indicated to me (PC 2020) that he shares these reservations: "Often the disguise of interdisciplinarity hides essentially disciplinary enterprises." Like another member of the team, Randviir in this journal (2020), Ilyin prefers transdisciplinarity: "Far more promising are attempts to develop what you describe as metadisciplinarity and I call transdisciplinarity."

One social semiotic rule for metadisciplinary debates is that people in dispute should not to try to settle matters by appealing to definitions. All three terms, interdisciplinarity, transdisciplinarity and metadisciplinarity should be used in their fuzzy inclusive sense, understood to be sufficiently similar and containing sufficient differences within each as between them all.

A recent UNESCO report on relations between humanities and science and technology reflected usefully on these terminological issues. Its chief investigator, Professor Peter Wells, Director of UNESCO's Higher Education section, identified a fundamental epistemological challenge, to "question strict Cartesian separations". He wrote:

"Beyond the paradigm of inter- and trans-disciplinarity we must re-draw the knowledge map, not to mix areas but to allow and facilitate their indispensable synergies." $(2019,52)$

Wells' team of 130 experts from across the globe represents a global perspective on disciplines and interdisciplinarity. This scale is itself a relatively new phenomenon. Wells identifies a deeper level, epistemology, in which he sees a "Cartesian divide" between humanities (interpretive) disciplines and STEM disciplines as they are often called. Wells' proposal is radical. He sees current efforts at interdisciplinarity as themselves just a paradigm. I use his study to sketch my own account of some features of metadisciplines in a metaparadigm framework:

1. Metadisciplinarity is not a zero-sum game, rearranging existing areas (disciplines, sub-disciplines) into new patterns without consequences. It aims to produce new knowledge maps, rethinking how existing categories map onto a newly understood reality, a whole not reducible to the sum of its parts.

2. This exercise aims to be productive, making new connections or disconnections which correspond better to how things are, and release new discoveries and energies.

3. Metadisciplinary knowledge maps are radically inclusive, including fields that otherwise are considered incompatible, and researchers with few social connections.

\section{TRANSFORMING DISCIPLINES}

There is an Irish joke about giving directions in which a lost tourist asks a local: "How do I get to Limerick?" "Well," the local replies, "Firstly, you wouldn't start from here."

Unfortunately, like the tourist, we always start from where we are, in this case, with the state of knowledge as it is, sets of disciplines, not an agreed metadiscipline. In this section I start with the three disciplines the Project proposes as sites for its disciplinary intervention: politics, biology, and linguistics. In the next sections I look at these proposed disciplines to see their potential to evolve into more metadisciplinary forms, and how social semiotics might assist this process. 
I introduce a social semiotic proposition here regarding disciplines. Disciplines can be understood as a set of signifiers of their objects, produced and maintained by the community of the discipline. They are held together in a complex dynamic system in which disciplines can affect reality and reality can affect systems, but not symmetrically. As Kuhn noted as a universal fact, this set of signifiers will never be adequate to the full set of objects. There will always be gaps, anomalies, which can provoke new forms of the system and new understanding of reality.

From this proposition comes a heuristic rule. Metaparadigm thinking and increases in knowledge come from identifying and investigating these gaps. Metaparadigm innovations grow from the gap between the way objects of a discipline are framed and the troubling knowledge that resists that framing.

\section{POLITICS}

I begin with the dyad Politics-Power to open up some metaparadigm reflections on politics as a discipline, using the Wikipedia definition of "political science" as reference point: "a social science which deals with systems of governance". This definition places the discipline in a hypotactic structure as a "social science", concerned with "governance", not power. To open up this well-defined discipline I bring out the generative ambiguities in "power" as the larger, more problematic set of potential objects of the discipline.

To do so I begin with the phrase "knowledge is power," which was a slogan for the conference which inspired this special issue. In spite of its inspirational value, I point out that this statement is implausible, inside or outside politics. In his opening address Professor Ilyin noted that this phrase is often attributed to Sir Francis Bacon, Viscount St. Albans, but that Bacon never actually said it. The closest he got was:

"Scientia et Potenctia humana en idem coincident, quia ignoratio causae destituit effectum." (Human knowledge and human power meet in one; for where the cause is not known the effect cannot be produced.)

Bacon wrote in the 17th century, announcing and influencing a scientific revolution which was beginning as he spoke, so he was a successful prophet. However, political power was another matter, as Bacon knew well. He ascended the slippery slope of power not through knowledge but through the support of powerful patrons, and he crashed when he lost that support. Bacon knew then that the idea that "knowledge is power" was just a fantasy for intellectuals from the margins. Not much has changed for intellectuals and academics today.

In keeping with the conditions of language of metaparadigm thinkers, as he was, his two key terms were radically ambiguous. "Scientia" then could mean "science" in the modern sense, which Bacon knew was not powerful, or knowledge in an open-ended sense. "Power" then as now had several senses, as did potenctia.
Bacon's version of the slogan "knowledge is power" is more careful but not more true, then as now. But now as then, political leaders who ignore science, as US President Trump did with Covid-19, find that they cannot control the material effects they refuse to understand.

Against this I put reflections on power by Michel Foucault, metaparadigm thinker and social semiotician (among other identities):

"Truth' is linked in a circular relation with systems of power which produce and sustain it, and to effects of power which it induces and which extend it. A regime of truth." (1980, 133)

Foucault is often interpreted as claiming the inverse of Bacon, that power is knowledge. This statement makes a more complex claim: that truth/knowledge and power are linked so closely that each is an effect of the other, in a complex reciprocal form. His proposition, with its complexity and fuzziness restored, brings out inherent issues for Politics and related disciplines reframed in metaparadigm thinking. Relations of power outside the discipline can affect theories and studies of power, in ways that will be invisible for "normal" political scientists. Metaparadigm-oriented political scientists will be more aware of influences from outside academia, and more aware that their discipline can have Baconian effects, able to influence as well as be subjected to power.

As with all metadisciplinary discussions of individual disciplines, this account does not attempt to be comprehensive or obedient to the views of current disciplinary authorities. To do so would be counterproductive, reinforcing precisely the divisions that block exchanges across different disciplines and paradigms.

\section{BIOLOGY}

The Project chose "Biology" as another discipline. This choice has many implications for understanding how disciplines can function and be modified within a metaparadigm framework.

"Biology" has a significant place in a traditional taxonomy of disciplines, though the Oxford English Dictionary records its first use in English at the beginning of the 19th century. In this hypotactic structure, biology occupies a high node within the sciences. In terms of this map, reframed through the modern paratactic division between STEM and HASS, Biology is far removed from both Politics and Linguistics, both vertically (Biology is a higher order discipline) and laterally (Biology is not closely cognate with either).

All such maps are constructed, not directly grounded in reality, and they can change over time. However, we can make useful fuzzy judgements on degrees of disciplinarity (or interdisciplinarity) in these terms. Movement across greater lateral or vertical taxonomic distances can be understood as more strongly interdisciplinary or transdisciplinary. Vertical movements are likely to be more difficult and consequential than lateral movements, along a fuzzy continuum. As a result, the 
Project's choice of Biology as one of its disciplines increases the challenge of their interdisciplinary intervention.

In this case, the Project hosted some experiments in more transdisciplinary research. One is by Alexander Spirov, not included in this special issue. He introduces his work on Evolutionary Computing as follows:

"The field of Evolutionary Computation (EC) has been inspired by ideas from the classical theory of biological evolution. In turn, impressive progress in EC field in understanding the reasons for efficiencies in evolutionary searches can be useful in life science." (Spirov, Myasnikova 2018, 94)

From a social semiotic perspective, I judge Spirov and his collaborator through what they do in what they say as indexical signs, not just what they say. Spirov's introduction is a metadisciplinary statement about the relation of these two fields, a transdisciplinary modification of both, understood as being in a complex, reciprocal relationship.

For Spirov, evolution is his field of application, a what-discipline in llyin's terms (PC 2020) whereas computing is his how-to discipline. In Project terms, Spirov's enterprise can be called a methodological, not a knowledge transfer. In this case, Spirov combines computing and biology, both STEM disciplines.

In this respect, this move could be seen as less radically interdisciplinary than combining Biology with HASS disciplines like Linguistics or Politics. However, in a metaparadigm framework, social semiotics can be seen to encompass digital signs and computing. Spirov brings a well-developed, stable interdiscipline, evolutionary computing, to the table. Mutually respectful interactions with metadisciplinary social semiotics could extend his promising experiment.

Suren Zolyan's work, in this issue (2020) and in related writings, is another experiment which expands the sense of how the Project can contribute to a stronger interdisciplinary theory and practice. As he explains, his article develops a "semiotic description of the genetic code" and this indeed is what he does. In this respect, he is using semiotics as a "how-to" discipline, in llyin's sense, applying it to biological content, a similar kind of crossover as Spirov's. He also proposes to work in the other direction, which would make this an especially complex piece of interdisciplinary research, though he does not obviously do that in this article.

In terms of my criteria for degree of interdisciplinarity, this connection seems to work mainly at the same hypotactic level, connecting two disciplines which are far apart. Zolyan does not label his work "biosemiotic", which could name a relevant interdiscipline. There are heuristic merits in his decision. In his analysis he works at a lower level in each large discipline, investigating two complementary forms in genetics and linguistics, bypassing the two disciplines as such. In this way he can produce ideas in a framework which is more fundamental than a relation between the two disciplines as such. This is metaparadigm work, moving freely between different levels and widely separated branches of the current organisation of disciplines.

My own work in social semiotics (2017) raises these issues. I propose there that linguistic theories of transformations would benefit by incorporating the latest scientific work on epigenetics $(2017,109)$. This could imply that I see social semiotics as a branch of biosemiotics or vice versa. I admire work currently done under that label. However, I find it more productive to propose an open metadisciplinary field, perhaps without a specific name, in which many connections can be made, vertically and horizontally, across the two fields currently named "social semiotics" and "biology".

\section{LINGUISTICS AND SOCIAL SEMIOTICS}

Two potential sites for developing a meaning meta-discipline are Linguistics and Social Semiotics. Linguistics names one of the three disciplines included in the Project. In some ways this is a sound choice. All human enterprises are social, and those social relations are mediated to a substantial extent through verbal language. Some linguistic expertise is needed in every metaparadigm. The same argument applies to social semiotics. In a metadisciplinary framework, boundaries weaken between the two. However, as disciplines they are social facts, trailing different histories and allegiances. In this section I compare them as candidate metadisciplines.

At times in its history linguistics has had metadisciplinary scope. As we saw, Kuhn made insightful use of Whorf's ideas. But multiple civil wars damaged Anglo-American linguistics since the 1950s (Harris 1993), and warring protagonists did not draw on linguistics as such as a common point of reference. This journal's title, "frontiers of linguistics", signals a fuzzy border around its concept of linguistics. This makes this journal better able to participate in metadisciplinary enterprises like this.

Another problem for linguistics as metadiscipline is its definitional exclusion of non-verbal language. Kuhn emphasised the role of non-verbal communication in paradigms. As Bruno Latour, semiotician of science, demonstrated (2005), knowledge production in science cannot be understood without looking at non-verbal modes. Science uses multimodal semiotics, to use the social semiotic term (Kress, Van Leeuwen 2002). Linguistics is impoverished by its exclusion of non-verbal language. However, if it included these modes, it would become semiotics.

Social semiotics is another candidate metadiscipline. Fomin, a key member of the Project team, in this issue (2020) described different forms of social semiotics, which he understands as a discipline that combines social and semiotic traditions. I use his expert review to make some points about social semiotics and metadisciplinarity.

Fomin argues that classic semiotics in both the Saussurean and Peircean traditions had a major place for society, while classic sociology as in Weber's work had 
a semiotic dimension. In a theory of metaparadigms, this suggests that founding fathers of what were to become distinct disciplines and schools had metadisciplinary perspectives, and moved away from this scope as they established their respective disciplines.

Metadisciplinarity is a fuzzy continuum, in which different instances can be ranged as more or less metadisciplinary. Fomin's work has a metadisciplinary tendency, and part of its value is that it leaves room to accommodate stronger metadisciplinarity, on his own as well as others" parts.

In his review, Fomin identifies three strands: Systemic Functional Linguistics/Social Semiotics (Halliday, Hodge, Kress and Van Leeuwen); the Tartu-Moscow School (Lotman, Randviir); and semiotic sociology (Heiskala) Using my criteria for metadisciplinarity derived from Wells, I point out that in this process Fomin drew a new map, including relationships between fields that no-one else knew existed. As a dynamic map it is productive, generating new knowledge, including, for myself, a new perspective on a discipline I have worked in for 30 years

The fuzzy whole that his map brings into view reveals two fissures I had not noticed so clearly before. One is a division between Anglo-American and European traditions, and a Russian tradition whose existence as a tradition I had not been aware of. I had known and admired many of the parts-e.g. Pavlov and Jakobson, Voloshinov/Bakhtin, Vygotsky, Lotman and Randviir-but the effect of this whole on its parts creates a rich new field. In Fomin's map this interacts further with the complex whole that is Anglo-American social semiotics, to produce a complex, dynamic international metadisciplinary field

This field, whose existence and scope I constructed from Fomin's text, is no longer exactly what he calls "social semiotics", yet can be described as a metadisciplinary version of that discipline. It puts together two strands, sociology and semiotics, which I had previously assumed too easily were eminently compatible. His discussion is an experiment which brings out more clearly than I had realised that the categories of social and semiotic resist being put together, even within social semiotics.

The binary whose resistance to crossing he reveals is not as fundamental as the Cartesian split between science and humanities disciplines, but is homologous. His history of social semiotics does heuristic work, indirectly showing the difficulty of this interdisciplinary project, his and mine. Unifying the social and the semiotic is a "wicked problem". Social semiotics turns out to be a site where definitions of the object and the discipline slip and slide, defeating efforts of its practitioners to offer simple, consistent definitions.

\section{SOCIAL SEMIOTIC PRACTICE}

Fomin (2020) criticized the "still quite limited scope" he saw in actual social semiotic analyses. Coming as this does from a friendly critic, this is a damning criticism of social semiotics, or a salutary demand that social semiotics should do better. Indeed, I see social semiotics as more a "how-to-discipline" in Ilyin's terms. The Project rightly insists on tight interconnections between knowledge and methodology. For Kuhn, the explanatory power of paradigm methods was decisive in its appeal to its community.

In what follows I clarify and deploy social semiotic methods in action. I draw mainly on some common tools and concepts found in different forms of semiotics and linguistics, all described in Hodge (2017). I illustrate four components of the Social Semiotic meta-toolkit: multiscalar analysis, whole-part analysis, transformations and multimodality. I reframe them as metadisciplinary terms and tools, each connected with each other and with other tools and concepts, made more powerful and precise by being situated in this context.

\section{MULTISCALAR ANALYSIS}

One controversial characteristic of social semiotic analysis in the Hodge/Kress/Van Leeuwen tradition has been close reading with a scale and intensity that is often called a weakness, especially when combined with wide-ranging inferences. How can so much interpretation be generated from such small data? This practice has roots in literary studies (e.g. "practical criticism"), in ancient hermeneutic traditions, religious and archaeological, and in modern (e.g. psychoanalysis, forensics). But an era which sees "quantitative" research as more "scientific" has led to fewer close reading practices, which are even less valued even by HASS disciplines.

In my recent work (Hodge 2017) I develop a radical multiscalar theory which has always been a tacit part of social semiotic disciplines. In linguistics, Halliday's theory was initially called rank-and-scale grammar. Chomsky's linguistics had a strong theory of scalar structures of the sentence, though little to say about structures and meanings above sentence level. In a multiscalar theory, linguistics and social semiotics must be able to talk about structures, meanings and referents too small or fast, or too large and slow to see.

This is a lesson all HASS disciplines can learn from sciences, in a convergence of paradigms that will transform current maps of knowledge. Physics over the 20th century found it needed to postulate processes and structures far below observed levels, down to unsuspected levels of the nanosphere, at the same time as it mapped tiny traces of the Big Bang 14 billion years ago. In biology, microbiology is revealing new structures on ever-smaller scales, while better explaining the billion-year trajectory of evolution. Metadisciplinary social semiotics needs multiscalar dimensions in theory and practice.

A powerful concept has become available to social semiotics from the metadiscipline of complexity theory: fractals (Mandelbrot 1977; Hodge 2017). Fractals are complex shapes which can be replicated, similarly but not identically, across potentially unlimited scales, to 
project undiscovered nanolevels or unimagined macrolevels. This model can guide and enable analysis. For instance, Zolyan's insightful analysis of similarities between genetic and linguistic "codes" compares similar levels in a multiscalar framework, noting that Crick's analogy collapsed the levels of paragraph and letter (Crick 1981, 48).

As often in metaparadigm conditions there is complex mutual interaction between theory and method. The model projects a world which motivates meticulous searches for objects so small that no-one outside that paradigm would work so hard or at all to look for them.

To illustrate with the challenge of Covid-19, this pandemic is triggered by an organism too small to be seen by the naked eye, whose effects act on macro-levels of global processes. The inexplicable link between extremely small and extremely large is too powerful to deny, yet impossible to understand and act on. Critics rightly emphasise the challenges arising from the unprecedented size of the problem. The intractability of this "wicked problem" is also compounded by the power of the nanosphere.

The strategy of the present article illustrates this principle. I mainly use microstructures from two short pieces of text as data from which to propose hypotheses to be tested on an account of a large enterprise (the Project), and the larger enterprise shared by contributors to this special issue. Both these levels are set in and illuminate fundamental problems of knowledge, in Russia and the West, from the present, from the last 100 and the last 500 years. It is a small basis for so huge a leap, and a large problem to be understood in all its levels.

\section{WHOLE-PART DYNAMICS}

The idea that "a whole is other than the sum of its parts" is usually seen as theory, not method, but it interweaves both, especially in metaparadigms. It goes back to Aristotle in 4th century BC, a philosopher, scientist, political theorist and semiotician combined, and a highly productive metaparadigm thinker. The principle has become important in various fields of science, as in Goethe's biology and Gestalt theories of perception. In Complexity Science it has become a central premise (Anderson 1972). It has long been a core idea in semiotics. Successive linguistic paradigms share the premise that the meaning of sentences is other than the sum of meanings of component words.

In this section I emphasize the connections of this powerful idea with social semiotic practice, especially as it bears on the central concern of the Project with knowledge transfer (translation, mediation, convergence), between knowers with different languages, disciplines and degrees of education. The core problem closely relates to problems of incommensurability, and whole-part thinking and analysis play a role in constructing or working around real-life problems of this kind.

Kuhn's theory of paradigms incorporates this principle. The claim that successive or alternative paradigms are incommensurable is based on the assumption that their various parts are so determined by the whole they are part of that they have incommensurably different meanings. This has implications for method. Kuhn looks for difference, even where others expect basic similarity. He then investigates elements in the respective wholes and empirically demonstrates difference. He does not always demonstrate empirically that this difference really matters, that it is an incommensurability.

"Parsing" names a traditional practice of linguistic analysis. The word comes from Latin pars, a part, so it refers to a practice that should be basic in whole-part analysis. It acquired a bad name in the Middle Ages associated with a pedagogic practice, where school children had to divide sentences into syntagmatic parts, subjects, verbs and objects, and identify their role in a taxonomy of parts of speech.

Parsing seemed pointless because these teachers did not know what the point was. Parsing is an elemental process, applied both to syntagmatic forms (strings of words in sentences, functionally-related parts of bodies or genes realised in organisms) and to paradigmatic forms (classifications of words and meanings, biological taxonomies).

All kinds of parsing share some characteristics. Boundaries between parts can be recognised before the whole is known, and conversely wholes can be grasped with an incomplete understanding of the parts. With all kinds of parsing, the practice gains point when successive acts of breaking down sentences into parts are related to acts of restoring wholes. This dialectic between parts and wholes is essential to productive whole-part analysis.

I explore implications for analysis and interpretation by looking again at the title of the special issue itself: "Evolution of human capacities to know and act". A first scanning of the sentence identifies a string of 8 words in English, constituting a provisional whole, a sentence. Further scans identify words which go together, forming larger wholes or sub-wholes.

I begin by seemingly increasing the complexity of the problem. This sentence is in English, but the first language of most authors is Russian, as probably with most readers. This observation reveals the complex bilingual nature of the journal issue, and the prior Project. For this reason, I add the Russian version, "Эволюция способностей людей познавать и действовать".

This seems to add complexity to an already complex situation, but the move illustrates a paradox of complexity analysis often found in social semiotic practice, especially in metaparadigm modes. Removing naturally occurring complexity can increase intractable complexity, and restoring it can make it more understandable. In this case the problem irreducibly involves interactions between wholes, different languages, English and Russian, scientific and humanities. To analyse these wholes separately removes the problem from the data, it cannot analyse it.

Professor Ilyin provided this analysis at my request. He commented: 
"Literally and word for word (articles absent as a major principle)-Evolution of capacities of people (humans-the same root as German Leute) to know (or rather learn, grammatically continuously) and act." (Ilyin PC 2020)

I begin by parsing both versions of the sentence, in English and Russian, adapting conventions that the linguist Chomsky used (1957) though did not invent:

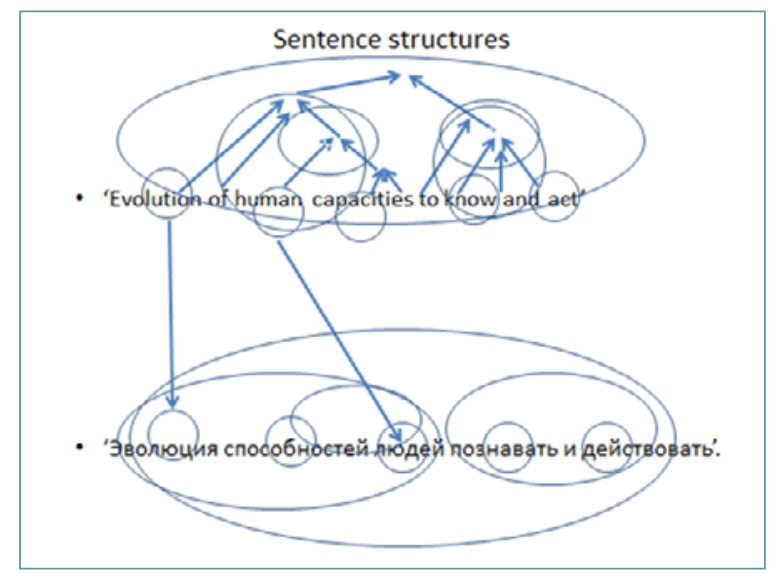

I have represented the sentences as a series of parts, each represented by a circle combining elements that go together. I identify each of these parts as distinct elements in an initial 4-step parsing operation. This works equally well in both languages, signifying homology. Above each element I indicate larger wholes, again marked by a circle. The circles at various levels build up to an overarching whole, the sentence itself. Within the English sentence I have marked the relationships that constitute the structure of this sentence.

This example allows some observations about whole-part analysis in social semiotic metaparadigm interpretive practice. As is evident in the diagram, no single whole determines the meaning of every word. On the contrary, circles of different sizes proliferate as parts and wholes. This leads to a transdisciplinary generalization: Whole-part relationships are constituted not by single wholes divided into parts, but multiple wholes at many levels. Each part is also a potential whole, affecting and affected by wholes it is a part of and by parts it subordinates.

At the heart of the commensurability thesis is the idea that different languages, in this case English and Russian, are such different wholes that individual words will have untranslatably different meanings. That is, the whole that is each language determines the effective meaning of all words. However, as linguists from all languages recognise, word meanings always depend on their contexts, their place in sentences.

"Evolution" and Эволюция subtly affect the meaning of "human" and людей. The pair of words in English and Russian respectively combine to narrow down the scope of "evolution" and Эволюция, to focus mainly on late stages of the process. Likewise, they empty the meaning of "human" and людей of many possible associations as strongly as does the difference between the
Russian and English words. Here it marks the boundary between human and prehuman species in evolutionary theory, in the process reducing the differences pointed out by Professor llyin.

There is another relevant pair of wholes the words potentially belong to. "Evolution" and Эволюция both belong to scientific discourses in the two languages, whereas "human" and людей belong to less specialist discourses. The two wholes of Russian and English each include discourses, scientific and non-scientific, and the scientific discourse of each is more homologous.

Again, the principle of incommensurability applies asymmetrically. It has been shown empirically that scientific English is less incommensurable to Russian scientists in a given field than it is to Russian non-scientists, and vice versa. Sometimes different wholes interact positively, enhancing communication. At other times the interaction is negative. Whole-part analysis does not propose a single outcome or interpretation but the contrary. It lays out the grounds for empirical analysis, it does not replace it.

The social dimension is crucial to social semiotic explanations because social wholes interact continuously with meanings as wholes, with important but unpredictable outcomes. Ilyin's translation, for instance, is an act of speech, to use the philosopher John Austin's term for his brilliant sociosemiotic insight (1962), where material and social dimensions can be reconstructed from uses of words, as indexical signs to use Peirce's useful term. This act is a whole linking speaker/actor to hearer/actor, which demonstrates llyin's professional courtesy and linguistic competence. He does not say here that he is a highly competent speaker of both languages, he demonstrates it.

He also provides empirical data for the incommensurability problem. Whole-part analysis has to accommodate the fact that the constitutive relationships are open, dynamic and unpredictable in multiscalar systems. The analysis can identify where the main problems lie and suggest work-arounds which might work. In this case the problems are indeed huge, as the theory predicts, but humans can get around them, as Ilyin and his team demonstrate.

\section{TRANSFORMATIONS}

A third metaparadigm tool associated with social semiotics is transformational analysis. "Transformation" comes from Latin "trans", across, and "forma", shape or form. As we saw, "trans" has similarities to "meta". Since "forma" referred to something which had pattern or structure, it connotes a relation between wholes. "Transformation" connects closely with whole-part thinking. In its extended, complex, fuzzy metaparadigm sense it refers to any change or movement between wholes (forms) and parts.

In this section I show how powerful and wide-ranging a methodological practice it can be in a metaparadigm framework. In the process I show differences in the concept and method between disciplinary and metaparadigm conditions. Proponents of disciplinarity claim that 
concepts and methods are more effective within their original discipline, and lose their focus in interdisciplinary uses. The case of "transformations" in the discipline of linguistics shows the opposite.

In disciplinary linguistics "transformation" is so closely associated with Chomsky, that its position as a part in that whole limits its range for other linguists. E.g., rival linguist Halliday polemically deleted this term from his theory because of its associations with Chomsky. Chomsky's initial version of transformation was crisp and linear, but later he modified his theory to weaken its meaning. A social semiotic metadiscipline (Hodge, Kress 1988, 1993) gave this term a broader range of meanings, with fuzzy boundaries and broader connections.

Chomsky and Derrida from different paradigms share the term "trace", as a similar part in different wholes. For Chomsky, some features of a text signify that a transformation has happened. Derrida (1967) refers to meanings "under erasure", i.e., specifically cancelled but still understood as having been cancelled. "Negation" is not a transformation for Chomsky, but it is for Derrida as for Freud and for epigenetic theory. As with Freud's theory of repression, this is always an action, part of whose meaning is the agency of this act. For Freud and Derrida, the meaning of such actions always refers to some agent. In classic semiotic terms they are motivated signs, Peirce's "indexical" signs.

All these differences can be seen as Chomsky's negations, which can be reversed to produce a far stronger account of language, which also connects better with many other areas of inquiry. I illustrate with an analysis of a sentence we have already looked at, "evolution of human capacities to know and to act". The analysis will begin by adapting Chomsky's linguistic model, but quickly becomes fuzzy, multimodal and multidimensional, to show both the intrinsic insufficiency of purely monomodal linguistics, and the explanatory power of metaparadigm analysis.

This sentence in English is interpreted by English speakers as a transformation of an underlying form:

[Immediate origin: The Project]

$\leftarrow 1$. (Human capacity to act and know) evolves

$\leftarrow 2$. Humans evolve/ humans act and humans know

The first transformation is reversed to reveal the picture organised in terms of a basic intransitive model of reality (Halliday 1978; Hodge, Kress 1993). This model represents non-linear causality, as in complexity theories of "emergence". This change has no effect on content, but changes the model, which is important.

The second transformation is more complex. It combines two prior sentences, each with a common subject, "human", and displaces "humans" as common subject. Transformational analysis makes one question clearer: who might be the agent of this repression and why?

This action displaces one term and reduces its number of occurrences, diminishing the salience of "humans" though not removing them. In this context we can ask: why would these HASS researchers seek to minimise precisely what makes their disciplines so important? One possible answer is that they show strategic deference to the dominant STEM researchers, within a higher education system that incorporates that dominance.

Another transformational process acts on the term "human". Attaching labels to phenomena is itself a transformational process, analysed in similar ways. "Human" here refers to a long chain of evolutionary history, focussing on a division between homo sapiens and other hominids.

Like all acts of classification this transformation carries ideological meanings. Here it implies the primacy of humans over all other species. There is a long series of other acts of classification which are "under erasure" here, including differences of gender, race, and nation (Russian, English, Australian etc.), plus differences of ability (intelligence), power, and education (including higher versus basic education, STEM versus HASS).

"Human" in this text is product and indexical sign of several powerful transformational operations. There are at least two transformations here, with different hypothetical agents and hence meanings. This analysis does not uncover certain meanings or truth. However, transformational analysis like other forms of social semiotic research plays an invaluable heuristic role, in a method in which empirical inquiry is essential, into a world in continuous transformation.

\section{MULTIMODALITY}

Social semiotics has built on foundational insights of semiotics to produce a powerful new concept and tool, multimodality (Kress, Van Leeuwen 2002). Semiotics' insistence that knowledge comes through all senses and modes has transformed earlier knowledge regimes. Kress and Van Leeuwen showed that even apparently mono-modal verbal language, in its most prestigious form, print, is in practice multimodal. Meanings produced by the linguistic system (grammar and vocabulary) are continuously intertwined with and modified by meanings from other semiotic modes. In the process they revealed the role of a hitherto-disregarded semiotic mode, the material organisation of signs as itself a set of signs.

I illustrate this method through analysing the three words for the three disciplines the Project identifies as sites or targets for intervention: "politics, biology, linguistics". These three words all have meanings and referents from the linguistic code. These meanings interweave with a code consisting of material, spatial signs which are more motivated, in Saussure's terms, but hitherto invisible without the luminol of multimodality theory.

For instance, order is a powerful though ambiguous motivated sign, applying to verbal as well as other codes. Firstness is a Peircean iconic sign with a fuzzy range of meanings, including priority or importance. "Politics" here has this position and meaning. Kress and Van Leeuwen report another common form in visual texts, centre-plus-periphery, in which the central term, biology, has this 
value. This ambiguity does not necessarily mean that one or other signifier is wrong. It may signify ambivalence on the part of producers.

A related indexical sign is the concrete fact that all three are included in a single string of three words, which implies (signifies) that they are separate but have a connection, with commas as complementary multimodal indexical signs. Together they signify a list of strongly bounded items in loose paratactic order.

Arranging elements alongside each other is one of the two most common forms of order in semiotics. The other is "hypotactic", which includes subordination of elements. When I discussed the meanings of these three disciplines for the Project, I connected them to versions of the dominant hypotactic disciplinary structure. My analysis here suggests a meaning from this material mode which is different from the implications drawn from verbal meanings. This is not a problem for multimodal analysis, but a strength. According to a basic rule of semiotics, everything can be a sign, and can convey meaning. In this case, these features of the text are like running commentary on meanings conveyed by words. They signify an attitude towards disciplinarity, that disciplines have strong boundaries and can be ordered any way in a list.

Both kinds of structure are Peircean icons, spatial signs. That is, the meanings signified by the project verbal text are spatial and multimodal. All taxonomies are spatial signifieds and signifiers even if communicated entirely by words. They also operate as indexical signs whose meaning comes from the actions that constitute them.

My earlier discussion (Biology) suggested some uncertainty about the shape and characteristics of the disciplinary taxonomy. This present multimodal analysis reinforces that suggestion. It implies and ambivalence towards the classic hierarchy, and to some extent destabilises or transforms it into a more paratactic structure. Paratactic structures favour the openness and dynamism of metaparadigm thinking, and this is what is signified by this strand in the multimodal complex.

The point of this analysis is not to propose this or any other interpretation as the single intended meaning of these three words in the project, but the contrary. All human communication is multimodal, weaving together messages in different modes that may be identical or complementary, or may be different or opposite. Multimodal analysis does not ignore meanings from the verbal channel. It just weighs them against other meanings which otherwise would not even be registered. In this case, different modes provide evidence that the Project team has problems with both disciplinarity and interdisciplinarity. And so they should, as metadisciplinary researchers.

\section{CONCLUSION}

As Zadeh recognised in his metadisciplinary attempt to bring semiotic and engineering systems together
(1973), the precision and certainty prized in disciplinary knowledge is incompatible with complexity and relevance. The constant confrontation between reality and forms of knowledge produces endless supplies of intractable anomalies and "wicked" problems without clear solutions. The Project should not be expected to provide simple, practical formulae for "knowledge transfer" or "methodological convergence". Better would be a transformation of relations between different kinds of researchers, in a comprehensive, open dynamic metaparadigm, in a supportive environment. I have suggested how social semiotics could play a significant role in such a process.

\section{REFERENCES}

Anderson, P. W., 1972. More is different. Science, 177(4047), 393-396.

Austin, J., 1962. How to do things with words. Oxford: Oxford University Press.

Bateson, G., 1973. Steps to an ecology of mind. London: Paladin.

Chomsky, N., 1957. Syntactic structures. The Hague: Mouton.

Conklin, J., 2006. Dialogue mapping. Chichester: Wiley. Crick, F., 1981. Life itself. New York: Simon and Schuster. Derrida, J., 1967. Of grammatology. Baltimore: Johns Hopkins University.

Eldridge, N. Gould, S., 1972. Punctuated equilibria. In Schopf, T. (Ed.), Models in paleobiology. San Francisco: Freeman, Cooper and Co.

Fomin, I., 2020. Sociosemiotic frontiers (this issue).

Foucault, M., 1980. Power/Knowledge. Brighton: Harvester.

Godfrey-Smith, P., 2016. Other minds. New York: Farrer, Strauss and Giroux.

Halliday, M., 1978. Language as social semiotic. London: Edward Arnold.

Harris, R., 1993. The linguistics wars. Oxford: Oxford University Press.

Hodge, B., 1978. Foreshortened Time. Cambridge: DS Brewer.

Hodge, B., 2017. Social Semiotics for a complex world. Cambridge: Polity.

Hodge, B., Kress, G., 1988. Social Semiotics. Cambridge: Polity.

Hodge, B., Kress, G., 1993. Language as Ideology. London: Routledge.

Hoyungen-Huene, P., 1993. Reconstructing scientific revolutions. Chicago: Chicago University Press.

Kress, G., Van Leeuwen, T., 2002. Multimodality. London: Bloomsbury.

Kuhn, T. S., 1977[1962]. The structure of scientific revolutions. Chicago: Chicago University Press.

Latour, B., 2005. Reassembling the social. Oxford: Oxford University Press.

Mandelbrot, B., 1977. The fractal geometry of nature. New York: W. H. Freeman.

Randviir, A., 2020. Sociosemiotics and metalanguage: the case of Translanguaging. 
Knowledge, complexity, power: social semiotics as metadiscipline

Shermer, M., 2002. This view of science. Social studies of science.

Spirov, A., Myasnikova, E., 2018. Evolutionary Computations and modular Organization of the Gene Regulatory Regions, 11th International Multiconference BGRS $\backslash S B$.

Wells, P., 2019. Humanities and Higher Education: synergies between humanities and science and technology. Higher Education in the world 7.
Whorf, B., Language, Thought and Reality, Cambridge, MA: MIT Press.

Zadeh, L., 1973. Outline of a new approach to the analysis of complex systems and decision processes. IEEE Transactions on Systems, Man and Cybernetics. Zolyan, S., 2020. From matter to form (Present issue).

Return to front page $\uparrow$ 